UDC 316.77

LBC 60.56

\title{
THE RUSSIAN-UKRAINIAN CRISIS: WAS THERE A MORAL PANIC?
}

\author{
Aleksandr A. Efanov \\ Orenburg State Pedagogical University, Orenburg, Russian Federation
}

\begin{abstract}
The article attempts to make a sociological analysis of the Russian-Ukrainian crisis, which began in February 2014 and is still ongoing. The subject of this study is the ratio of strategies covering the RussianUkrainian crisis in news and information programs of the Federal TV channels ("Novosti", "Vremya", "Vremya pokazhet" (Pervyy kanal); "Vesti", "Vecher" s Vladimirom Solovyevym" (VGTRK ("Rossiya 1", "Rossiya 24")); "Segodnya", "Mesto vstrechi" (NTV)) and reactions of society to them. Used the complex of methods: quantitative content analysis, discourse analysis, series of online surveys in the social network "VKontakte" "Panic social moods and television" $(n=400)$. Chronological framework of the study: December 2014 - December 2016.

On the ground of the author's sociological study it is concluded, that the Russian-Ukrainian crisis has provoked one of the types of a moral panic - a panic social moods - as a result of risks concerning the viability of society, the potential threat of social boundaries destruction. This topic kept the first place in the "agenda" for more than two years. However in 2016 due to the relative stabilization of the situation in Ukraine the volume of airtime to the coverage of this issue in news programs of the Federal channels decreased 7 -fold. The level of panic social moods in relation to the Russian-Ukrainian crisis decreased in 3 times (in 2014 this question was concerned $69 \%$ of respondents, in $2016-21 \%$ ). Thus, it can be assumed that the decline in media interest will inevitably lead to a recession of panic social moods attitude to the Russian-Ukrainian crisis, the gradual development of personality of social immunity to this phenomenon.
\end{abstract}

Key words: moral panic, Russia, Ukraine, crisis, mass media.

УДК 316.77

ББК 60.56

\section{РОССИЙСКО-УКРАИНСКИЙ КРИЗИС: БЫЛА ЛИ МОРАЛЬНАЯ ПАНИКА?}

\section{Александр Александрович Ефанов}

Оренбургский государственный педагогический университет, г. Оренбург, Российская Федерация

\begin{abstract}
Аннотация. В статье предпринимается попытка социологического осмысления российско-украинского кризиса, начавшегося в феврале 2014 г. и продолжающегося до сих пор. Предметом рассмотрения в настоящем исследовании является соотношение стратегий освещения российско-украинского кризиса в информационных и общественно-политических программах федеральных телеканалов («Новости», «Время», «Время покажет» (Первый канал); «Вести», «Вечер» с Владимиром Соловьевым» (ВГТРК («Россия 1», «Россия 24»)); «Сегодня», «Место встречи» (НТВ)) и реакций общества на них. Используется комплекс методов: количественный контент-анализ, дискурс-анализ, серия онлайн-опросов в социальной сети «ВКонтакте» на тему «Панические социальные настроения и телевидение» $(n=400)$. Хронологические рамки исследования: декабрь 2014-го-декабрь 2016 года.

На основании авторского социологического исследования делается вывод, что российско-украинс․ кий кризис спровоцировал панические социальные настроения как один из типов моральной паники в 궁 pезультате рисков в отношении жизнеспособности общества, потенциальной угрозы разрушения соци¿ альных границ. Что касается социальных изменений, в 2014 г. было проведено авторское социологическое « исследование методом полуструктурированного интервью, в ходе которого эксперты (менеджеры раз\%ै личных типов СМИ, интернет-активисты, преподаватели кафедры журналистики, а также руководители 胥 социологических центров и лабораторий $(n=10))$ отметили консолидацию общества в результате россий(9) ско-украинского кризиса.
\end{abstract}


Более двух лет данная тема сохраняла за собой первое место в повестке дня. Однако в 2016 г. вследствие относительной стабилизации обстановки на Украине в информационных программах федеральных телеканалов в семь раз сократилось количество эфирного времени на освещение этого вопроса. Уровень панических социальных настроений в отношении российско-украинского кризиса также снизился в три раза (в 2014 г. данной проблемой были обеспокоены 69 \% респондентов, в 2016 г. - 21 \%). На основании проведенного исследования автор прогнозирует, что падение медиаинтереса неизбежно может привести к рецессии панических социальных настроений в отношении российско-украинского кризиса, постепенной выработке у индивидов социального иммунитета к данному явлению.

Ключевые слова: моральная паника, Россия, Украина, кризис, СМИ.

2014 год ознаменовал собой начало затянувшегося российско-украинского кризиса, спровоцировавшего ухудшение геополитических связей на мировой арене. Кровавые события на Майдане, разделившие украинцев на два противоборствующих лагеря, свержение действующего президента В. Януковича и приход к власти команды П. Порошенко побудили правительство России вмешаться в конфликт с миротворческой миссией. Провозглашение Донецком и Луганском своей независимости, а также присоединение Крыма и Севастополя к составу Российской Федерации окончательно ухудшили взаимоотношения с ведущими западными и европейскими державами, посчитавшими, что в условиях украинской раздробленности российские власти преследуют свои исключительно корыстные интересы.

Информационная война, развернувшаяся в общемировом медиапространстве, создавала в сознании россиян иллюзию приближения реальной войны, когда под угрозой оказалась целостность социальных границ. Результаты исследования ВЦИОМ в 2016 г. показали, что общество больше всего опасается международной напряженности, конфликтов между странами и военных действий (23\%). При этом только $21 \%$ респондентов уверены, что такое случится (25\% опрошенных предполагают, что это, скорее всего, произойдет) [3].

Согласно ранее предложенной типологизации реакции общества на российско-украинский кризис представляют собой один из типов моральной паники - панические социальные настроения, которые проявляются «в результате возникаемой опасности в отношении сохранения неимущественных социальных благ - жизнеспособности общества и каждого его отдельного индивида» [6, с. 65]. Панические социальные настроения обусловлива- ют дисфункцию ориентирующих и регулирующих механизмов, когда рациональная составляющая в осознании явлений и процессов сменяется эмоциональной, а сами движения индивидов приобретают массовый характер. Делается акцент на бесконтрольности, в результате чего общественными движениями начинает управлять инстинкт самосохранения.

Предметом рассмотрения настоящего исследования является соотношение стратегий освещения российско-украинского кризиса в информационных и общественно-политических программах федеральных телеканалов («Новости», «Время», «Время покажет» (Первый канал) [7]); «Вести», «Вечер» с Владимиром Соловьевым» (ВГТРК («Россия 1», «Россия 24»)) [2]; «Сегодня», «Место встречи» (НTB) [1] и реакций общества на них. Используется комплекс методов: количественный контент-анализ, дискурс-анализ, серия онлайн-опросов в социальной сети «ВКонтакте» на тему «Панические социальные настроения и телевидение» $(n=400)$. Контент-анализ построен на фиксировании маркеров: Россия, Украина, война, Майдан, Донбасс, Донецк, Луганск, Крым, Севастополь. Анализ осуществлялся на основе материалов сайтов телеканалов - «интернет-дублеров», оперативно размещающих сюжеты сразу после их выхода в телевизионный эфир; кроме того, на сайтах можно проследить частотность: сколько раз та или иная новость освещалась в информационных выпусках и общественно-политических программах в конкретный день, подавалось ли событие «в развитии» - с новыми подробностями и героями. Хронологические рамки исследования: декабрь 2014-го - декабрь 2016 года.

Как показали результаты контент-анализа, пристальное внимание общественности к событиям на Украине началось с 18 февраля 
A.А. Ефанов. Российско-украинский кризис: была ли моральная паника?

2014 г., когда, несмотря на старт Олимпийских игр в Сочи, провозглашавших мир во всем мире, произошли кровопролитные столкновения в Киеве (рис. 1-3).

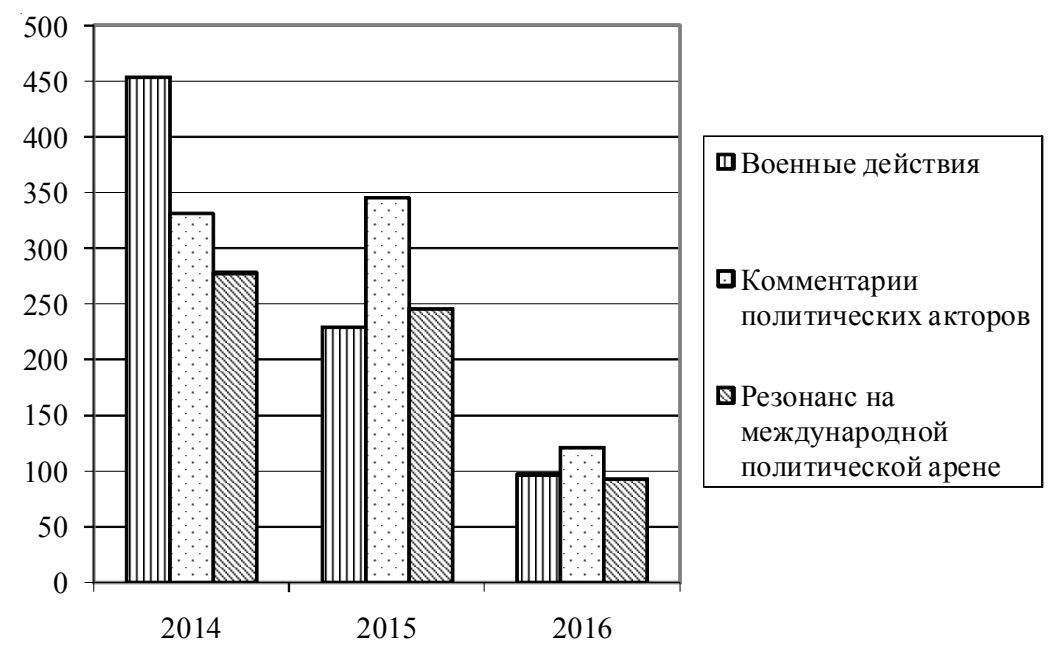

Рис. 1. Контекст и динамика освещения российско-украинского кризиса в эфире Первого канала

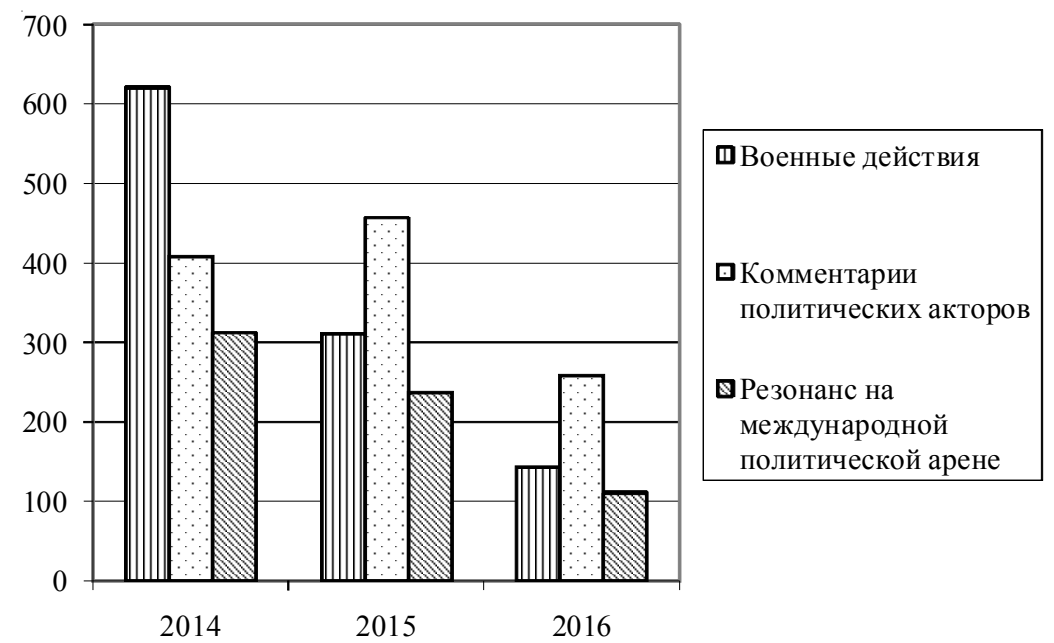

Рис. 2. Контекст и динамика освещения российско-украинского кризиса в эфире ВГТРК («России 1», «России 24»)

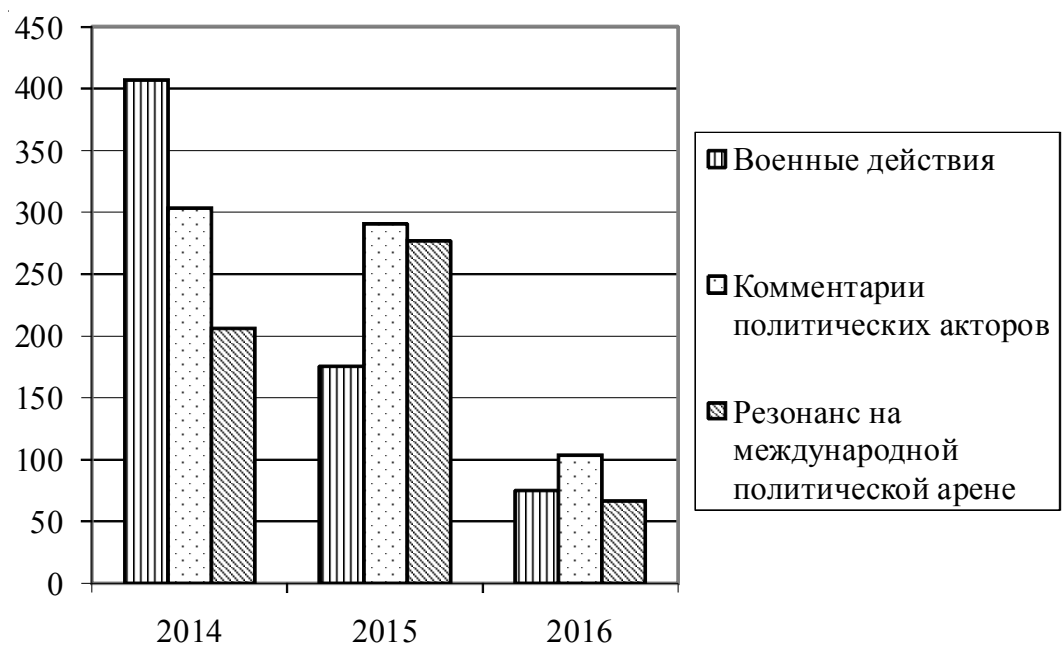

Рис. 3. Контекст и динамика освещения российско-украинского кризиса в эфире НТВ 
Наибольшая частотность освещения российско-украинского кризиса отмечена в эфире телеканалов ВГТРК («России 1», «России 24»). Это объясняется в первую очередь стратегией программной политики - доминантой информационных и общественно-политических программ (в остальном все представленные телекомпании в той или иной степени имеют государственную форму собственности, вследствие чего отражают интересы действующей власти).

Если рассматривать контекст освещения, можно заметить, что в 2014 г. (в момент начала российско-украинского кризиса) все телеканалы делали акцент на кадрах военных действий, представляя репортажи корреспондентов из «горячих точек» (Киева, Донецка, Луганска и т. д.). Исходя из аудиовизуальной природы телевидения данные материалы, изобилуя зрелищной «картинкой», привлекали особое внимание аудитории (что продиктовано первичной потребностью общества - стремлением к безопасности и защищенности).

Для достижения максимальной эффективности медиаконтролеры применяли риторику опасности: «Вчерашние братья-украинцы сегодня превращаются в российских врагов» («Россия 1»); «Смута накрыла “матерь городов русских” - Киев» (Первый канал); "Обезумевшие бандеровиы бьют всех, без разбора» (НТВ); «Новая украинская власть без стеснения готова претендовать на российские земли» («Россия 1»).

Для конституирования медиакартины и провоцирования аффективных реакций использовались комментарии политических акторов как первых лиц государства в информационных программах, так и представителей более низких рангов (депутатов, лидеров политических движений и пр.) преимущественно в общественно-политических программах. Следует отметить, что в 2014 г. на всех федеральных телеканалах «появились дискуссионные общественно-политические программы ("Время покажет" на Первом канале; "Место встречи" на НТВ; авторское телевизионное шоу В. Соловьева "Воскресный вечер" стало выходить практически ежедневно и было переименовано в “Вечер"), увеличились их хронометражи (нередко до 3-4 часов эфирного времени в день)» $[5$, с. 76$]$.
На дискуссионных площадках политические акторы активно использовали стратегию дискредитации противника, оперируя ироничной риторикой, нередко со стилистически сниженной лексикой: «Цирк Порошенко» («Россия 1»); «Новое Правительство Украины уже расписалось в своей несостоятельности» («Россия 1»); «Смутный век» Крыма завершен» (НТВ); «На что способно новое Правительство Украины? Разве что морды бить и конфеты производить?!» (Первый канал).

Кроме того, все представленные телеканалы уделяли особое внимание освещению резонанса на международной политической арене: это и заявления лидеров европейских и западных государств, и введение санкций против России, и заседания НАТО и ООН (впоследствии данные прецеденты также получали обсуждение на дискуссионных площадках общественно-политических программ).

В подобных материалах применялась как риторика опасности: «Запад ополчился на Россию» (Первый канал); «Европа увидела в лице России кровного врага» (НТВ); «Это будет уже не гонка вооружений. Это будет гонка, кто первым нажмет на ядерную кнопку» («Россия 1»), так и риторика неразумности: «Они пытаются перекрыть нам кислород, а в итоге мы перекроем им газ» («Россия 1»); «Да что может старая Европа?! Лишь только преклоняться перед теми, кто сильнее...» («Россия 1»); «Эти люди в Госдепе политикой занимаются или в кукольный театр играют?!» (НТВ); «Судя по всему, политика точно не их конек...» (Первый канал).

В 2016 г. ввиду относительной стабилизации обстановки на Украине телеканалы делали акцент на комментариях политических акторов и резонансе на международной политической арене в попытках поддерживать медиаинтерес к явлению, повторяя самые зрелищные кадры столкновений в Киеве и на Донбассе прошлых лет и выдвигая прогнозы дальнейшего разворачивания событий. При этом российско-украинский кризис в основном обсуждался в рамках общественно-политических программ. По сравнению с 2014 г. в информационных программах в семь раз сократилось эфирное время на освещение событий 
на Украине. Нередко данная тема полностью отсутствовала в выпусках новостей.

Для соотношения стратегий освещения российско-украинского кризиса в поле телевидения и реакций общества на них была проведена серия онлайн-опросов «Панические социальные настроения и телевидение» $(n=$ $400)$ в социальной сети «ВКонтакте» в декабpe 2014-го и декабре 2016 г. (см. таблицу).

Согласно результатам опроса в 2014 г. наибольшую обеспокоенность и тревожность в обществе провоцировали новости в отношении российско-украинского кризиса (69 \%). Вторую позицию заняли сообщения о взаимоотношениях со странами Запада и Европы (18\%). На третьем месте оказалась медиарепрезентация экономического кризиса в России $(11 \%)$.

Кроме того, респондентам был задан открытый вопрос: «Почему данные новости вызывают у вас обеспокоенность и тревожность?» Так, 75 \% опрошенных подчеркивали угрозу Третьей мировой войны («До Третьей мировой недалеко»; «Высока вероятность мировой войныл»; "Ситуация с Украиной может разжечь международныи вооруженный конфликт» и т. п.). $25 \%$ респондентов делали акцент на опасности социальной дезорганизации внутри страны («Это подрывает стабильность в обществе»; «Экономический кризис может спровочировать соичиальный упадок»; «В бедной стране высок риск разгула преступности» и т. п.).

Что касается 2016 г., то особую обеспокоенность стали вызывать новости о взаимоотношениях России со странами Запада и Европы (39 \%). Вторую строчку заняли сообщения, связанные с освещением военной операции в Сирии (26\%). При этом можно констатировать снижение уровня панических социальных настроений в отношении российскоукраинского кризиса. На данное явление об- ращали внимание только $21 \%$ респондентов. Полученные результаты можно объяснить с точки зрения изменения медиастратегий основных федеральных телеканалов, которые стали уделять большее внимание освещению геополитической ситуации (особенно в период предвыборной кампании в США и начала президентства Д. Трампа).

В свою очередь панические социальные настроения смог вызвать новый прецедент антитеррористическая миссия против ИГИЛ (запрещенной в РФ организации). Отвечая на открытый вопрос о мотивации выбора варианта ответа, $79 \%$ респондентов также подчеркивали угрозу Третьей мировой войны, но в отношении иной первопричины («Mиротворческая миссия в Сирии может обернуться для нас войной»; "Россия потревожила террористов, как улей пчел. И теперь боевики ИГ могут ополчиться на весь мир»).

Не меньший интерес представляет динамика выбора последнего варианта ответа. Если в 2014 г. не смотрели телевизор только $2 \%$ опрошенных, то в 2016 г. их стало $11 \%$. Причины сознательного отказа пользователей Интернета от «традиционного» средства массовой коммуникации нуждаются в глубоком социологическом осмыслении и доказательности в рамках дальнейших исследований.

Результаты проведенного исследования позволяют сделать вывод, что российско-украинский кризис стал основой для конструирования панических социальных настроений как одного из типов моральной паники, когда под угрозой оказалась жизнеспособность общества, безопасность каждого его отдельного индивида. Что касается социальных изменений, в 2014 г. было проведено авторское социологическое исследование методом полуструктурированного интервью, в ходе которого эксперты (менеджеры различных типов

Распределение ответов на вопрос: «Телевизионные новости на какую тему
вызывают у вас наибольшую обеспокоенность и тревожность?»
\begin{tabular}{|l|c|c|}
\hline \multicolumn{1}{|c|}{ Варианты ответов (в \%) } & 2014 г. & 2016 г. \\
\hline Российско-украинский конфликт & 69 & 21 \\
\hline Взаимоотношения со странами Запада и Европы & 18 & 39 \\
\hline Экономический кризис в стране & 11 & 3 \\
\hline Военная операция в Сирии & - & 26 \\
\hline Не смотрю телевизор & 2 & 11 \\
\hline
\end{tabular}


СМИ, интернет-активисты, преподаватели кафедры журналистики, а также руководители социологических центров и лабораторий $(n=10))$ отметили консолидацию общества в результате российско-украинского кризиса: «Ситуацию вокруг Крыма можно считать конструктивными последствиями для общества. У нас очень долго не было национальной идеи, которая объединяла бы людей» [4, с. 41].

Более двух лет данная тема сохраняла за собой первое место в повестке дня. Однако в 2016 г. вследствие относительной стабилизации обстановки на Украине в информационных программах федеральных телеканалов в семь раз сократилось количество эфирного времени на освещение этого вопроса. Уровень панических социальных настроений в отношении российско-украинского кризиса также снизился в три раза (в 2014 г. данной проблемой были обеспокоены 69 \% респондентов, в 2016 г. - $21 \%$ ). Таким образом, можно предположить, что падение медиаинтереса неизбежно приведет к рецессии панических социальных настроений в отношении российско-украинского кризиса, постепенной выработке у индивидов социального иммунитета к данному явлению.

\section{СПИСОК ЛИТЕРАТУРЫ}

1. АО «Телекомпания НТВ». - Электрон. дан. - Режим доступа: http://www.ntv.ru/ (дата обращения: 06.01.2017). - Загл. с экрана.

2. «Вести» : интернет-газета ("VESTI.RU”).Электрон. текстовые дан. - Режим доступа: http:// www.vesti.ru/ (дата обращения: 06.01.2017). - Загл. с экрана.

3. Главные страхи россиян: война и экономика // ВЦИОМ, 2016. - Электрон. текстовые дан. - Режим доступа: $\mathrm{http}$ ://wciom.ru/index.php?id=236\&uid=115584 (дата обращения: 06.01.2017). - Загл. с экрана.

4. Ефанов, А. А. Моральные паники как социокультурный феномен современного информационного общества / А. А. Ефанов // Наследие Ю. И. Селезнева и актуальные проблемы журналистики, критики, литературоведения, истории : материалы Третьей Междунар. науч.-практ. конф. (Краснодар, 23-24 сент. 2016 г.). - Краснодар : Новация, 2016. - С. 38-41.

5. Ефанов, А. А. Примат информационно-аналитических программ в современном поле телевидения / А. А. Ефанов // Коммуникация в современном мире : материалы Всерос. науч.-практ. конф. «Проблемы массовой коммуникации», 11-13 мая
2017 г. Ч. I / под общ. ред. В. В. Тулупова. - Воронеж : Факультет журналистики ВГУ, 2017. - С. 76-77.

6. Ефанов, А. А. Структурная типологизация моральных паник как прецедентов социальной действительности / А. А. Ефанов // Вестник Бурятского государственного университета. - 2014. -№ 6(1). - С. 65-69.

7. Первый канал. - Электрон. дан. - Режим доступа: https://www.1tv.ru/ (дата обращения: 06.01.2017). - Загл. с экрана.

\section{REFERENCES}

1. AO «Telekompaniya NTV» [NTV Telecompany JSC]. URL: http://www.ntv.ru/. (accessed January 6, 2017).

2. Internet-gazeta "VESTI.RU” [VESTI.RU E-Newspaper]. URL: http://www.vesti.ru/. (accessed January 6, 2017).

3. Glavnye strakhi rossiyan: voyna i ekonomika [The Main Fears of Russians: War and Economy]. URL: http://wciom.ru/index.php?id=236\&uid=115584. (accessed January 6, 2017).

4. Efanov A.A. Moralnye paniki kak sotsiokulturnyy fenomen sovremennogo informatsionnogo obshchestva [Moral Panics as a SocioCultural Phenomenon of the Modern Information Society]. Nasledie Yu.I. Selezneva i aktualnye problemy zhurnalistiki, kritiki, literaturovedeniya, istorii: materialy Tretyey Mezhdunar. nauch.-prakt. konf. (Krasnodar, 23-24 sent. 2016 g.) [Legacy of Yu.I. Seleznev and Current Issues of Journalism, Critics, Literary Studies, History: Proceedings of the $3^{\text {rd }}$ International Scientific and Practical Conference (Krasnodar, Sept. 23-24, 2016)]. Krasnodar, Novatsiya Publ., 2016, pp. 38-41.

5. Efanov A.A. Primat informatsionnoanaliticheskikh programm $\mathrm{v}$ sovremennom pole televideniya [The Primacy of Information and Analytical Programs in the Modern Field of Television]. Tulupov V.V., ed. Kommunikatsiya v sovremennom mire: materialy Vseros. nauch.-prakt. konf. «Problemy massovoy kommunikatsii», 11-13 maya 2017 g. Ch. I [Communication in the Modern World: Proceedings of the All-Russian Scientific and Practical Conference "Problems of Mass Communication", May 11-13, 2017. Part 1]. Voronezh, Fak. zhurnalistiki VGU Publ., 2017, pp. 76-77.

6. Efanov A.A. Strukturnaya tipologizatsiya moralnykh panik kak pretsedentov sotsialnoy deystvitelnosti [Structural Typologization of Moral Panics as Precedents of Social Reality]. Vestnik Buryatskogo gosudarstvennogo universiteta, 2014, no. 6(1), pp. 65-69.

7. Pervyy kanal [First Channel]. URL: https:// www.1tv.ru/. (accessed January 6, 2017). 


\section{Information About the Author}

Aleksandr A. Efanov, Candidate of Sociological Sciences, Associate Professor, Department of Journalism, Orenburg State Pedagogical University, Pushkinskaya St., 18, 460000 Orenburg, Russian Federation, yefanoff_91@mail.ru.

\section{Информация об авторе}

Александр Александрович Ефанов, кандидат социологических наук, доцент кафедры журналистики, Оренбургский государственный педагогический университет, ул. Пушкинская, 18, 460000 г. Оренбург, Российская Федерация, yefanoff_91@mail.ru. 